\title{
A CIRCULAÇÃO DA LITERATURA BRASILEIRA NOS ESTADOS UNIDOS: o caso da série literatura brasi- leira em tradução da Tagus Press
}

Maria Alice Gonçalves Antunes Universidade do Estado do Rio de Janeiro

\section{RESUMO}

Artigos publicados em diversos jornais e revistas virtuais revelam os primeiros anos do século XXI como um período de especial importância para a circulação da literatura brasileira em tradução para a língua inglesa nos Estados Unidos, em especial. Parece-nos também que o cenário de lamentação constante causado pelo número limitado de traduções de literatura brasileira publicadas em inglês começou a sofrer alteração expressiva nos dezessete primeiros anos do século XXI. Neste artigo, procuramos compreender melhor a circulação da literatura brasileira no mundo anglófono, nos primeiros anos deste século. Para tal, tomaremos as ideias dos estudiosos André Lefevere e Johan Heilbron para examinar o caso da Brazilian Literature in Translation Series publicada pela Tagus Press, entre 2013 e 2014, nos Estados Unidos.

PALAVRAS-CHAVE: Tradução; Reescrita; Literatura brasileira

\section{Introdução}

Artigos publicados em diversos jornais e revistas virtuais revelam os primeiros anos do século XXI como um período de especial importância para a literatura brasileira em tradução para a língua inglesa. Na revista Language Magazine, Kristal Bivona (2012) destaca que "a literatura brasileira está se tornando cada vez mais disponível em tradução”. Na edição 
virtual do jornal britânico The Guardian, Ángel Gurría-Quintana (2014) declara que "vivemos um momento promissor para a escrita brasileira em tradução". Para Bivona e Gurría-Quintana, vários fatores podem justificar o interesse na literatura brasileira. Entre eles, podemos citar a realização da Copa do Mundo no Brasil em 2014 e das Olimpíadas no Rio de Janeiro em 2016, o 50 aniversário do golpe militar em 2014 (tema de romances da literatura brasileira traduzidos para o inglês tais como $K$ (2013) de Bernardo Kucinski, por exemplo), o Brasil como convidado de honra na Feira Internacional do Livro de Frankfurt em 2013, além da atuação de empresas internacionais, tais como a Amazon, que olham o momento do Brasil como um mercado de publicação digital inexplorado.

Destacamos ainda a publicação, em 2012, da edição intitulada The Best of Young Brazilian Novelists do periódico literário trimestral britânico Granta Magazine com trechos vertidos para o inglês da produção de vinte jovens escritores brasileiros. Uma equipe de sete juízes "altamente qualificados, independentes, ativos em campos diferentes do mundo literário" (FEITH; FERRONI, 2012) foi formada para selecionar vinte jovens escritores brasileiros de prosa literária em língua portuguesa, com no mínimo uma história publicada no Brasil e com até quarenta anos de idade à época da publicação do volume. A equipe contou entre seus membros com a escritora e roteirista Beatriz Bracher; o escritor e historiador Benjamin Moser; o escritor Cristovão Tezza; o professor e então editor chefe da EdUERJ, a editora da Universidade do Estado do Rio de Janeiro, Italo Moriconi; o jornalista, crítico literário e escritor Manuel da Costa Pinto; o escritor Marcelo Ferroni; e com o tradutor e professor da Universidade de São Paulo, Samuel Titan Jr. Os jovens autores escolhidos pela equipe para integrar a edição The Best of Young Brazilian Novelists foram Cristhiano Aguiar, Javier Arancibia Contreras, Vanessa Barbara, Carol Bensimon, Miguel del Castillo, J. P. Cuenca, Laura Erber, Emilio Fraia, Julián Fuks, Daniel Galera, Luisa Geisler, Vinicius Jatobá, Michel Laub, Ricardo Lísias, Chico Mattoso, Antonio Prata, Carola Saavedra, Tatiana Salem Levy, Leandro Sarmatz e Antônio Xerxenesky. Além da publicação dos contos (em língua portuguesa) na edição da Granta Magazine, a produção dos escritores selecionados foi publicada em dois volumes, um em inglês e outro em espanhol.

Além de todos os motivos aqui destacados, que certamente impulsionam a publicação da literatura brasileira nos sistemas literários de língua inglesa, Robert Feith e Marcelo Ferroni (2012) mencionam a econo- 
mia próspera de então e a sempre vibrante música brasileira como fatores que contribuem para que o Brasil (e a literatura brasileira) atraia a atenção internacional nos primeiros anos do século XXI.

As pesquisas acadêmicas também revelam o início do século XXI como um período promissor para a literatura brasileira em tradução para o inglês, em especial. Em artigo intitulado "O Papel da Patronagem na Difusão da Literatura Brasileira: o Programa de Apoio à Tradução da Biblioteca Nacional” (2008), Marcia A. P. Martins frisa que "a presença dos livros e autores brasileiros no mercado internacional está aumentando, embora mais em termos de diversidade do que propriamente de volume de vendas" (p. 41). No periódico Modern Languages Open, Cinara Valim de Melo revela as descobertas de sua pesquisa de viés historiográfico sobre a literatura brasileira traduzida para o inglês no início do século XXI. Segundo a pesquisadora, entre os anos 2010 e 2014, são publicadas "vinte e sete traduções" (2017), um número próximo do total de traduções publicadas em toda a década anterior. Valim de Melo vai além dos motivos já aqui elencados e destaca três fatores significativos que afetam sobremaneira a tradução e a publicação de obras brasileiras no mundo anglófono nos primeiros anos deste século. Em primeiro lugar, ela destaca o sucesso de vendas de Paulo Coelho e a consolidação de seu nome como um dos escritores brasileiros mais conhecidos no mundo inteiro; em seguida, sublinha as retraduções da obra de Clarice Lispector, organizadas por Benjamin Moser. Para Valim de Melo, a organização realizada por Moser identifica Lispector como a "maior representante do cânone brasileiro da world literature" (2017). Valim de Melo conclui ressaltando o aumento do número de traduções da obra de autores brasileiros contemporâneos. Tal aumento resulta ainda, na visão da autora, das premiações conquistadas por esses autores no Brasil e no exterior, do trabalho de agentes literários, de tradutores, de editoras, e da participação do Brasil nos festivais internacionais e nas feiras literárias.

Por outro lado, Johan Heilbron destaca que o texto literário é visto como um produto de circulação arriscada porque está inexoravelmente ligado a uma língua (2015, p. 297). Além disso, o texto proveniente do Brasil sempre teve sua circulação ainda mais complicada pela pertença a um mercado literário periférico, com menos de $1 \%$ dos originais traduzidos para a língua inglesa. A posição do texto literário escrito em língua portuguesa é diferente, por exemplo, daquela ocupada pelo inglês, escrito em uma língua que ocupa uma posição hiper-central, e cuja produção 
responde por 6 em cada 10 livros traduzidos para outras línguas. O texto literário produzido no Brasil ocupa uma posição diferente também dos textos gerados em alemão e em francês, línguas vistas como centrais, cuja produção literária responde por $10 \%$ dos livros traduzidos para outras línguas; é diferente ainda de outras línguas vistas como semi-centrais (russo, espanhol, italiano, sueco) que têm entre $1 \%$ e $3 \%$ dos livros traduzidos para outras línguas $(2015$, p. 297). Entretanto, apesar de tais fatos, o cenário de lamentação acerca da posição periférica da língua portuguesa e do consequente número reduzido de traduções de títulos da literatura brasileira publicadas em inglês começa a sofrer alteração expressiva nos primeiros anos do século XXI.

Neste artigo, procuramos compreender melhor a circulação da literatura brasileira no mundo anglófono nos primeiros anos deste século. Para tal, tomamos as ideias dos estudiosos André Lefevere e Johan Heilbron para examinar o caso da Brazilian Literature in Translation Series publicada pela Tagus Press, entre 2013 e 2014, nos Estados Unidos.

\section{Reescrita e patronagem}

No artigo intitulado "Mother Courage's Cucumbers. Text, System and Refraction in a Theory of Literature" (2000), Lefevere define as "refrações" (p. 233) como adaptações de uma obra literária a um público leitor diferente do original que têm como objetivo sugestionar a interpretação da obra. A tradução, a edição e a antologização de textos, a compilação de histórias da literatura e as obras de referência, as biografias e as resenhas são refrações ou recursos que viabilizam e estimulam a circulação de um texto literário e que promovem o processo de canonização de obras e autores. Para Lefevere, as "refrações" (p. 233) desempenham uma função de grande valor no crescimento das literaturas. O estudioso lança questões, a nosso ver, essenciais tais quais: "como uma refração realmente funciona? E que implicações a refração poderia trazer para uma teoria da literatura?" (p. 235). Em Tradução, Reescrita e Manipulação da Fama Literária (2007), Lefevere novamente examina o tema e introduz o termo "reescrita" para se reportar às mesmas práticas. Além disso, declara que as reescritas se revelam uma frágil conexão entre a "alta" literatura e o leitor não profissional (p. 18). Ao longo dos anos, reescritores projetam imagens de um escritor, de uma obra, de um período, de um gênero e, às vezes, de toda uma literatura, e essas imagens almejam atingir um público distinto daquele que o original correspondente de maneira geral atinge. 
Por isso, a análise das reescritas não pode ser desprezada. É indispensável que pesquisemos quem as escreve, por que as escreve, sob que condições as escreve e para que público se direcionam (LEFEVERE, 2007, p. 19). É imperiosa, em especial, a necessidade de pesquisas que busquem detalhes acerca dos patronos dessas demandas.

Para a análise das reescritas, Lefevere baseia-se na noção de sistema, "um conjunto de elementos inter-relacionados que compartilham certas características que os distinguem de outros elementos vistos como não pertencentes ao sistema" (1985, p. 225). Para Lefevere, a literatura pode ser vista como um sistema que atua segundo um conjunto de limitações, já que é formado por elementos (livros, por exemplo) e por pessoas "que leem, escrevem e reescrevem livros" (p. 226). Por conseguinte, o sistema atua com um conjunto de limitações sobre leitores, escritores e reescritores. O sistema literário é igualmente um dos sistemas que constitui o "(super)sistema conhecido como sociedade" (p. 226). Dito de outra forma, uma cultura, uma sociedade é o universo do sistema literário. Este e os outros sistemas que se vinculam ao sistema social são abertos uns aos outros: eles se influenciam mutuamente.

Segundo Lefevere, há duas fontes de controle que possibilitam que o sistema literário não perca demais o passo em relação aos demais subsistemas que fazem parte da sociedade. Um fator de controle integra o sistema literário e procura controlá-lo a partir de seu interior, dentro dos parâmetros definidos pelo segundo elemento, que está fora desse sistema. O primeiro fator corresponde aos leitores profissionais: os intérpretes, os críticos, os resenhistas, os professores de literatura, os tradutores - enfim, os reescritores em geral. Em certas ocasiões, tais profissionais condenarão obras literárias porque essas obras vão contra o conceito dominante de literatura - a poética - ou contra a ideologia, a visão de mundo em certo período da história de uma sociedade. Todavia, segundo Lefevere, é mais costumeiro que os reescritores adequem as obras literárias à poética e à ideologia de uma dada época (1985, p. 226).

O segundo fator de controle, que opera na maior parte das vezes fora do sistema literário, é a patronagem, algo próximo dos poderes (no sentido foucaultiano) que podem impulsionar ou proibir a leitura, a escrita e a reescrita de literatura. A patronagem é formada por três elementos que se relacionam em várias combinações: o ideológico (papel exercido por qualquer tipo de censura, por exemplo), o econômico (papel exercido por reis, agências governamentais) e o de prestígio, ou status (que faz com o 
reescritor seja integrado a uma elite) (LEFEVERE, 1985, p. 227); e pode ser exercida por pessoas, por grupos de pessoas, uma organização religiosa, um partido político, uma classe social, uma corte real, editores e, por último, mas não menos importante, pela mídia, tanto os jornais e as revistas como as grandes corporações de televisão. De acordo com Lefevere,

os patronos raramente tentam influenciar um sistema literário de forma direta. Geralmente operam por meio de instituições criadas para regular a escrita ou pelo menos a distribuição da literatura: academias, agências de censura, revistas críticas e o estabelecimento educacional. (1985, p. 227).

A patronagem pode ser indiferenciada ou diferenciada. É indiferenciada quando seus três componentes são concedidos pelo mesmo patrono, como no caso dos estados totalitários contemporâneos ou de monarcas no passado. A patronagem é diferenciada quando o triunfo econômico, por exemplo, é relativamente independente de fatores ideológicos, e não traz necessariamente status em seu rastro, como são exemplos os autores de best-sellers contemporâneos (1985, p. 227).

Como afirma Martins (2010), as ideias de Levefere

com respeito à interação da tradução com a cultura e suas estruturas de poder são fundamentais para se entender o papel das editoras e das instituições que, através de incentivo e patrocínio, interferem nas decisões editoriais e na implementação de políticas culturais (p. 65).

Destacamos, portanto, que as ideias de Lefevere continuam atuais desde que foram lançadas e seguem aplicáveis à análise de casos como aquele que apresentamos aqui.

\section{Fluxos culturais periferia-centro}

Para Johan Heilbron, "a circulação internacional de bens culturais geralmente exibe uma estrutura centro-periferia" (2015, p. 297). Entretanto, as trocas interculturais e a consequente circulação de capital cultural não ocorrem de forma homogênea, já que tais trocas enfrentam obstáculos que diferem de forma quantitativa e qualitativa. Se a língua ocupa uma posição central no mercado das trocas internacionais, haverá muitas traduções para línguas estrangeiras, mas poucas traduções para essa língua central. Ou seja, o mercado central tende a ter menos interesse na produção cultural estrangeira e por isso traduz pouco para a própria língua (HEILBRON, 2015, p. 297). Por outro lado, o processo inverso ocorre 
com muita frequência. Traduz-se muito do inglês, uma língua hiper-central, para outras línguas.

Já os bens culturais provenientes de mercados periféricos ou não hegemônicos, os livros em especial, precisam superar entraves no caminho para a publicação em um sistema tido como hiper-central, como é o de língua inglesa. Esse trajeto, segundo Heilbron, além de mais difícil do que o inverso, é também pouco conhecido, pois tem recebido pouca atenção por parte de pesquisadores da área dos Estudos da Tradução, por exemplo. Martins é uma das pesquisadoras da área que se dedica à pesquisa sobre as trocas culturais entre o sistema literário brasileiro (não hegemônico) e os sistemas literários hegemônicos. Para ela, as trocas culturais - como da produção literária - entre sistemas hegemônicos e não hegemônicos geralmente tem como resultado um saldo negativo:

Este é o caso da literatura brasileira: além de pouco divulgada e consumida no exterior, tem contribuído para criar imagens e representações parciais e estereotipadas da nossa cultura, diante dos autores e temáticas comumente selecionados para tradução e que contam, ainda, com o reforço da mídia e do cinema. (2008, p. 39)

Diante de tal quadro, considero relevante a pesquisa aqui apresentada. Compreender melhor a circulação da literatura brasileira nos EUA e o caso específico da Brazilian Literature in Translation Series publicada pela Tagus Press, entre 2013 e 2014, pode contribuir de maneira decisiva para a seleção mais crítica de autores e temáticas para tradução e publicação no mundo anglófono.

Heilbron apresenta uma abordagem multidimensional que possibilita um exame cuidadoso do percurso de publicação de uma reescrita proveniente de um mercado não hegemônico. A abordagem envolve três níveis de análise: macro, médio e micro (2015, p. 298).

No nível macro, o pesquisador dirige-se à "estrutura centro-periferia" (HEILBRON, 2015, p. 297) que integra o sistema global de tradução, bem como ao equilíbrio de poder entre as forças (línguas, nações e povos) inseridas nesse sistema. Nesse nível, rivalidades entre sistemas vistos como centrais podem determinar o percurso que o texto literário proveniente de um sistema não hegemônico fará antes de atingir um sistema hiper-central como o inglês. É o que acontece no caso da literatura holandesa, publicada em dois sistemas centrais, o alemão e o francês, antes da publicação em inglês. Segundo Heilbron, os sistemas alemão e o francês competem por possíveis ganhos provenientes da circulação 
de produtos culturais originários de outras regiões, a Holanda, no caso (p. 299). Para o pesquisador, é provável que as traduções para o alemão e para o francês tenham servido de exemplos para as traduções para o sistema hiper-central, o inglês (p. 299). Ademais, para Heilbron, é mais provável que as obras literárias traduzidas para o francês e para o alemão e publicadas nesses sistemas, em primeiro lugar, sejam em seguida traduzidas para o inglês. É possível que outras obras, não publicadas na França ou na Alemanha, mercados que concentram prestígio e crédito literários, e culturas mais abertas a outras, como aponta Pascale Casanova (2002), podem deixar de atingir o mercado hiper-central de língua inglesa.

A análise no nível médio envolve a produção do conhecimento acerca da publicação e das estratégias usadas por editoras de portes diferentes na aquisição de traduções e de direitos autorais (HEILBRON, 2015, p. 300). Ou, nas palavras de André Lefevere, nesse estágio analisam-se os patronos e as suas escolhas. Fatores tais como o nível de vendas e o sucesso de crítica no sistema literário de origem, ou seja, o capital econômico e o capital cultural de um livro atuam de maneira direta para alavancar (ou desencorajar) a publicação de um autor e de sua obra no mercado hiper-central (HEILBRON, 2015, p. 300). Além desses, patronos como instituições governamentais de diversas ordens e os programas de incentivo lançados por essas instituições podem estimular a tradução e a posterior publicação de uma ou de várias obras. Heilbron (2015, p. 300) demonstra que o sucesso econômico e de crítica no sistema literário holandês são vistos como fatores preponderantes para a seleção de um autor/obra e posterior publicação em um sistema central. A publicação, por sua vez, dá-se por editoras de porte pequeno que tenham certa afinidade temática, por assim dizer, com as publicações da editora do produto original (p. 301).

No Brasil, a troca dá-se de forma um pouco diversa, já que o governo brasileiro também atua como patrono relevante. Em seu artigo, Martins apresenta o Programa de Apoio à Tradução da Biblioteca Nacional, criado em 1984. Tal Programa "tem como objetivo incentivar editoras estrangeiras a publicar obras brasileiras" (2008, p. 45) e, com o apoio do Ministério da Cultura, oferece ainda, além de bolsas de incentivo à tradução, "uma oportunidade não só de expandir o cânone brasileiro mais clássico, como de fugir dos estereótipos tradicionais associados à nossa cultura" (2008, p. 49).

Vemos assim que os patronos diferentes atuam com estratégias distintas para a divulgação da literatura do país de origem. Se a literatura 
holandesa parece mover-se de maneira independente, por assim dizer, no Brasil, a literatura que circula no exterior depende - também - de forte apoio do governo brasileiro.

No último nível, o nível micro, o pesquisador debruça-se sobre os diferentes atores envolvidos no processo de tradução, desde a seleção da obra até a publicação e recepção da mesma no sistema literário estrangeiro (HEILBRON, 2015, p. 302): "editores, críticos literários, agentes, tradutores $[\ldots]$ os verdadeiros intermediários entre o autor estrangeiro e o novo público". Ou, nas palavras de Lefevere, os reescritores que contribuem de forma direta para a construção da visibilidade internacional de autores (obras e literaturas). Entre esses intermediários, no entanto, Heilbron destaca os editores, "aqueles que fazem a seleção do conjunto globalmente disponível de literatura estrangeira e, portanto, funcionam como os 'guardiões' reais do sistema literário" (2015, p. 302).

À luz das ideias de Lefevere e de Heilbron, examinemos agora o caso da série publicada pela Tagus Press, em especial.

\section{0 caso da série Literatura Brasileira em Tradução da Tagus Press}

A Tagus Press é o braço editorial do Center for Portuguese Studies and Culture da Universidade de Massachussetts/Dartmouth. O Centro dedica-se ao estudo da Língua, Literaturas e Culturas dos países de língua portuguesa. Segundo o site da Universidade de Massachussetts, o Centro é referência na "divulgação da literatura, da história e da cultura portuguesas a um público de língua inglesa”. A Tagus Press divulga a literatura e a cultura portuguesas através de publicações e, entre elas, das séries, tais como a Brazilian Literature in Translation Series, a Adamastor Series, a Portuguese in the Americas Series e a Portuguese Language Textbook Series. Nas quatro séries foi publicado um total de quarenta títulos nos dezessete primeiros anos do século XXI nas áreas de Ciências Sociais, História e Literatura, além de um livro didático para o ensino de língua portuguesa como segunda língua. Vemos, assim, que a editora tem um papel de especial destaque na difusão das literaturas e culturas de língua portuguesa nos Estados Unidos, com especial produção nos primeiros anos do século XXI. É importante, assim, evidenciar o papel da patronagem exercida pela Universidade de Massachussetts, que escolhe, através da sua editora universitária, fomentar não só a leitura da literatura 
e da cultura, mas também o ensino da língua portuguesa como língua estrangeira, por meio do lançamento de um livro didático. Em sua tese de doutorado intitulada "The virtual image: Brazilian literature in English translation", a estudiosa da tradução Heloisa Gomes Barbosa (1994) apontava "o papel vital das universidades e seu patrocínio não só na produção de livros em geral, mas também na produção de obras literárias em particular" (p. 123). Tal papel pode também ser apontado como muito relevante nos dias de hoje. A atuação da Universidade de Massachussetts/ Dartmouth não deixa dúvidas acerca do comportamento visto pela universidade como necessário à divulgação das obras e da cultura de língua portuguesa.

Neste artigo, nosso principal interesse é a série de literatura brasileira em tradução e, assim, passamos a descrever suas características a partir deste ponto. De acordo com o site da universidade norte-americana, a Brazilian Literature in Translation Series "publica traduções de obras clássicas e contemporâneas da literatura brasileira com ênfase em autores contemporâneos". A série publicada entre 2013 e 2014 teve um editor brasileiro, o professor associado do Instituto de Letras da Universidade do Estado do Rio de Janeiro, João César de Castro Rocha. O professor de literatura comparada foi também o editor executivo da revista Portuguese Literary \& Cultural Studies publicada pela Tagus Press. Sobre o professor, a página da Academia Brasileira de Letras afirma que João César de Castro Rocha é detentor de vários títulos. Entre eles, podemos citar: "Hélio and Amélia Pedroso / Luso-American Foundation Endowed Chair in Portuguese Studies" (University of Massachussetts - 2009); “Tinker Visiting Professor" (University of Wisconsin, Madison - 2003); "John D. and Rose H. Jackson Fellow" (Yale University, Beinecke Library - 2001). Destacamos ainda que o professor recebeu em 2014 o prêmio Ensaio e Crítica Literária da Academia Brasileira de Letras e em 1998 o Prêmio Mário de Andrade da Biblioteca Nacional. É inegável que as premiações de João César de Castro Rocha bem como sua atuação como professor universitário tiveram papel importante na sua escolha como editor da série. Destacamos aqui que o papel do editor, tal como observamos anteriormente, é tido como fundamental no processo de publicação. É ele quem escolhe os autores e os títulos que serão publicados. Como afirma Heilbron, o papel do editor "tem importância especial” (2015, p. 302), já que é ele quem toma a principal decisão acerca do processo de publicação: que autor/obra será publicado/a. 
Em entrevista informal realizada no Instituto de Letras/UERJ, João César de Castro Rocha confirma que teve liberdade para selecionar os autores e os títulos que fizeram parte da Brazilian Literature in Translation Series, mas menciona também ter sido procurado por tradutores que trabalhavam em projetos específicos (como Alison Entrekin, por exemplo) e procuravam não só divulgar a tradução, mas também (e talvez principalmente) encorajar a publicação dos romances que traduziam. Sobre a atuação de tradutores e estudiosos de obras e autores brasileiros, Marcia A. P. Martins comenta que "também contribuem de forma incisiva para divulgar a nossa literatura no exterior" (2008, p. 43). Martins menciona o papel desempenhado por Clifford Landers, "um grande entusiasta da nossa literatura" (p. 43) que trabalha para divulgar a literatura brasileira entre o público leitor norte-americano e os editores. Alison Entrekin parece desejar contribuir dessa forma ao procurar o editor da série publicada pela Tagus Press. Além dos tradutores, João César de Castro Rocha menciona ainda que alguns títulos já haviam sido oferecidos à editora antes que o processo de seleção para a publicação na série tivesse início, sem mencionar, contudo, os títulos oferecidos. Infelizmente, não foi possível obter maiores esclarecimentos acerca do processo de seleção das obras publicadas pela Brazilian Literature in Translation Series, além daqueles oferecidos por João César de Castro Rocha. Assim, desconhecemos maiores detalhes acerca dos caminhos seguidos pelos profissionais que ofereceram títulos à Tagus Press.

Quatro romances e um livro de contos foram publicados pela série da Tagus Press. São eles: Winning the Game and Other Stories (Rubem Fonseca / Clifford Landers, 2013), Sea of Death (Jorge Amado / Gregory Rabassa, 2013), The Only Happy Ending for a Love Story is an Accident (João Paulo Cuenca / Elizabeth Lowe, 2013), The Eternal Son (Cristovão Tezza / Alison Entrekin, 2013), Crimes of August. A Novel (Rubem Fonseca / Clifford Landers, 2014). Destacamos alguns aspectos da lista de autores e obras publicadas pela Tagus Press: a seleção de uma obra de Jorge Amado, o "primeiro escritor brasileiro a conseguir sucesso comercial nos Estados Unidos" (LOWE, 2013, p. 120); a escolha de duas obras de Rubem Fonseca, vencedor do Prêmio Camões (2003), o que pode dever-se a uma boa aceitação da obra de Fonseca entre o público leitor (de obras traduzidas) norte-americano e/ou ainda à incisiva atuação do tradutor Clifford Landers como agente, ele mesmo grande responsável pela divulgação da obra de Rubem Fonseca nos EUA, papel muitas vezes 
assumido por tradutores de literatura brasileira e pelo próprio Landers, como apontamos acima. Outro aspecto interessante da Brazilian Literature in Translation Series é o equilíbrio entre as obras que abriram o mercado internacional à tradução de literatura brasileira, como Mar Morto / Sea of Death de Jorge Amado (LOWE, 2013, p. 120), até as obras e os autores que representam uma geração mais recente da literatura brasileira, como João Paulo Cuenca, um dos vinte jovens escritores brasileiros apresentados na edição intitulada The Best of Young Brazilian Novelists do periódico literário trimestral britânico Granta Magazine, conforme descrevemos na introdução a este artigo. Finalmente, destacamos que os títulos da Brazilian Literature in Translation Series da Tagus Press trazem nas páginas iniciais a informação de que foram publicados com o "apoio do Ministério da Cultura do Brasil / Fundação Biblioteca Nacional". Segundo Martins, a ação mais efetiva da Fundação Biblioteca Nacional tem sido o Programa de Apoio à Tradução de Livros Brasileiros no Exterior. O programa tem, entre outros objetivos, o de "difundir a literatura brasileira no exterior, criando um público leitor para o autor nacional" (MARTINS, 2008, p. 45) e, como aponta Martins, pode ajudar a "expandir o cânone literário brasileiro mais clássico, como [a] fugir dos estereótipos tradicionais associados à nossa cultura" (p. 49). De fato, cremos que as obras selecionadas por João César de Castro Rocha apontam tanto para certa expansão do cânone literário brasileiro como também para a fuga dos estereótipos tradicionais associados com frequência à cultura brasileira. A inclusão do autor João Paulo Cuenca, um jovem escritor, junto ao de Jorge Amado indica, a meu ver, uma tentativa de expansão do cânone literário brasileiro. Ao mesmo tempo, o romance Mar Morto (1936) / Sea of Death (2013) de Jorge Amado, selecionado para publicação, é um dos primeiros lançados pelo romancista e não figura nas listas dos mais vendidos do autor. Além disso, foge dos estereótipos tão frequentemente associados à segunda fase criativa de Jorge Amado, iniciada com o romance Gabriela, Cravo e Canela (LOWE, 2013, p. 121).

Realçamos, finalmente, o papel das universidades que atuam junto às instituições governamentais brasileiras como patronos para a divulgação da literatura brasileira no exterior. No caso da Brazilian Literature in Translation Series, três são os patronos de destaque: a Universidade de Massachussetts/Dartmouth, a Universidade do Estado do Rio de Janeiro e o Ministério da Cultura / Fundação Biblioteca Nacional. A Universidade de Massachussetts/Dartmouth tem, por assim dizer, um planejamento 
editorial que atende à divulgação da literatura e cultura de língua portuguesa a um público de língua inglesa, como demonstrei anteriormente; a Universidade do Estado do Rio de Janeiro participa de certa forma indiretamente através do trabalho do professor associado que se torna $o$ editor da série com características inovadoras; o governo brasileiro, através do Ministério da Cultura / Fundação Biblioteca Nacional apoia as traduções e, dessa forma, a divulgação da literatura brasileira no exterior. As universidades e o governo brasileiro exercem papeis fundamentais na patronagem para aumentar a visibilidade de autores brasileiros nos EUA.

Devemos salientar, finalmente, que não aparecem na Brazilian Literature in Translation Series romances de autoria feminina. É de certa forma surpreendente que nenhuma das jovens romancistas apresentadas pela Granta Magazine tenha uma obra entre aquelas publicadas pela série da Tagus Press.

\section{Considerações finais}

Neste artigo, tratamos da circulação da literatura brasileira nos Estados Unidos através da análise do caso da série de literatura brasileira em tradução publicada pela Tagus Press, editora da Universidade de Massachussetts/Dartmouth. A série, publicada nos anos 2013 e 2014, é uma iniciativa que busca aumentar a visibilidade da literatura brasileira nos EUA.

Podemos observar, em primeiro lugar, que os primeiros anos do século XXI parecem promissores para a literatura brasileira por razões que variam desde aquelas de cunho político-econômico até as de origem literária e musical, por assim dizer. A realização da Copa do Mundo de futebol no Brasil, dos Jogos Olímpicos no Rio de Janeiro, a participação do Brasil como convidado de honra da Feira Internacional do Livro de Frankfurt, o aniversário de 50 anos do golpe militar, a edição da The Best of Young Brazilian Novelists da Granta Magazine, a descoberta do mercado brasileiro digital pela Amazon, além da atuação de agentes literários, editores, tradutores e os próprios autores são motivos que chamaram a atenção do mundo editorial para o Brasil e ajudaram a impulsionar a divulgação da literatura brasileira. Um dos resultados desse momento de prosperidade foi a publicação da Brazilian Literature in Translation Series.

Observamos que a série de literatura brasileira traduzida reuniu autores de gerações diferentes da literatura brasileira, desde Jorge Amado até João Paulo Cuenca. Amado, conforme salientamos, foi o primeiro au- 
tor brasileiro a despontar nas listas de autores mais vendidos no exterior, e Cuenca é tido como um dos melhores da nova geração de autores brasileiros. Por outro lado, lamentamos, por assim dizer, a ausência de escritoras na seleção de romances publicados. Curiosamente, nenhuma das jovens escritoras apresentadas pela Granta Magazine tem uma obra entre aquelas lançadas na Brazilian Literature in Translation Series.

Destacamos ainda o papel dos tradutores na circulação da literatura brasileira. É possível que a publicação de dois títulos de autoria de Rubem Fonseca revele o resultado do trabalho de Clifford Landers, divulgador ativo da literatura brasileira, em geral, e da obra de Rubem Fonseca, em particular, nos EUA. Como afirma Martins, Landers diz que para ele o que "importa é chegar aos leitores e ter o privilégio de promover a cultura brasileira através das obras traduzidas" (2008, p. 43). Como podemos ver através da série Brazilian Literature in Translation Series, o trabalho de Landers vem dando resultados, especialmente se considerarmos sua atuação junto a editores e editoras e sua divulgação da obra de Rubem Fonseca.

A publicação da Brazilian Literature in Translation Series também demonstra o forte papel da patronagem exercida pelas universidades norte-americana e brasileira - em conjunto com o Ministério da Cultura / Fundação Biblioteca Nacional. A forte patronagem é necessária à divulgação da literatura brasileira, mas não pode se restringir à publicação da série. Autores e obras precisam "sair" da editora e atingir o público leitor não profissional através de outras formas de reescrita, além da tradução. A participação em antologias, a participação dos autores em feiras literárias, a publicação do trabalho em formatos digitais são caminhos que precisam ser percorridos por autores e autoras com o auxílio dos patronos que desejam ver a exportação da literatura brasileira se expandir, como vemos acontecer nos primeiros anos do século XXI. 


\section{THE CIRCULATION OF BRAZILIAN LITERATU- RE IN THE UNITED STATES: the case of the Tagus Press Brazilian literature in translation series}

\section{ABSTRACT}

Articles published in several online journals and magazines reveal the first years of the 21 st century as a period of special importance for Brazilian literature in English translation, in the United States, in particular. It also seems to us that the scenario of constant complaints caused by the few translations of Brazilian literature published in English began to undergo significant change in the first seventeen years of this century. In this article, we aim at enriching our understanding of the circulation of Brazilian literature in the Anglophone world in the early years of this century. To do so, we will take the ideas of two important translation scholars, André Lefevere and Johan Heilbron, to examine the case of the Brazilian Literature in Translation Series published by Tagus Press between 2013 and 2014 in the United States.

KEYWORDS: Translation; Rewriting; Brazilian literature

\section{REFERÊNCIAS}

BARBOSA, Heloisa Gomes. The virtual image: Brazilian literature in English translation. 381f, Tese (Doutorado - Centre for British Comparative Cultural Studies) Universidade de Warwick, Coventry, 1994.

BIVONA, K. Brazilian Literature Goes Global. Language Magazine. Malibu, 2012. Disponível em: $<$ https://www.languagemagazine.com/reading-brazil-digitally-and-in-translation/>. Acesso em: 29 nov. 2016.

CASANOVA, Pascale. A república mundial das letras. Tradução por Marina Appenzeller. São Paulo: Estação Liberdade, 2002.

FEITH, R.; FERRONI, M. Foreword. The Best of Young Brazilian Novelists. Granta Magazine 121. London, 2012. Disponível em: <https://granta.com/foreword-the-best-of-young-brazilian-novelists/>. Acesso em: 20 nov. 2016.

GURRÍA-QUINTANA, A. "Brazil does books as well as football”. London, 2014. 
Disponível em: <https://www.theguardian.com/books/booksblog/2014/jun/05/ brazil-does-books-as-well-as-football-world-cup>. Acesso em 29 nov. 2016.

HEILBRON, Johan. Fiction from the periphery: how Dutch writers enter the field of English-language literature. Cultural Sociology, v. 9, n. 3, p. 296-319, 2015.

LEFEVERE, A. Tradução, reescrita e manipulação da fama literária. Tradução por Claudia Matos Seligmann. Bauru, SP: EDUSC, 2007.

. "Mother Courage's Cucumbers. Text, System and Refraction in a Theory of Literature". In: VENUTI, L. The translation studies reader. Londres: Routledge, 2000. Cap. 18, p. 233-49.

. Why Waste Our Time on Rewrites? The Trouble of Interpretation and the Role of Rewriting in an Alternative Paradigm. In: HERMANS, T. The manipulation of literature: studies in literary translation. Londres: Croom Helm, 1985. Cap. 1, p. 215-248.

MARTINS, M. A. P. “O papel da patronagem na difusão da literatura brasileira: o programa de apoio à tradução da Biblioteca Nacional”. In: GUERINI, A.; TORRES, M.H.; COSTA, W. C. Literatura traduzida \& literatura nacional. Rio de Janeiro: 7Letras, 2008, p. 39-52.

VALIM DE MELO, C. Mapping Brazilian Literature Translated into English. Modern Languages Open. Liverpool, 2017. Disponível em: <DOI: http://doi. org/10.3828/mlo.v0i0.124>. Acesso em 20 abr. 2017.

Recebido em: 23/08/2018

Aceito em: 02/12/2019 